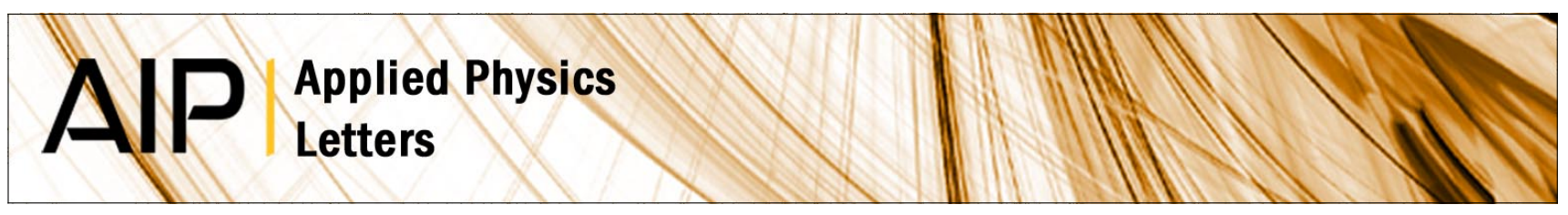

\title{
Indium-zinc-oxide nanobelts with superlattice structure
}

B. Alemán, P. Fernández, and J Piqueras

Citation: Appl. Phys. Lett. 95, 013111 (2009); doi: 10.1063/1.3176974

View online: http://dx.doi.org/10.1063/1.3176974

View Table of Contents: http://apl.aip.org/resource/1/APPLAB/v95/i1

Published by the AIP Publishing LLC.

Additional information on Appl. Phys. Lett.

Journal Homepage: http://apl.aip.org/

Journal Information: http://apl.aip.org/about/about_the_journal

Top downloads: http://apl.aip.org/features/most_downloaded

Information for Authors: http://apl.aip.org/authors

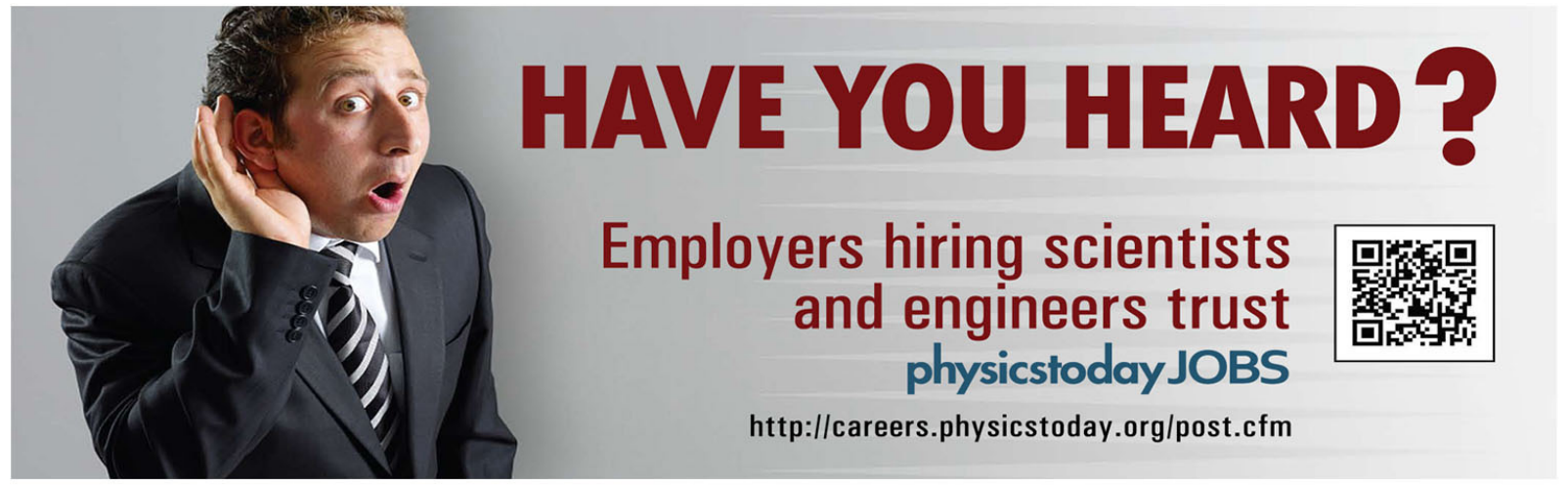




\title{
Indium-zinc-oxide nanobelts with superlattice structure
}

\author{
B. Alemán, ${ }^{\text {a) }}$ P. Fernández, and J Piqueras \\ Departamento de Física de Materiales, Facultad de Ciencias Físicas, Universidad Complutense de Madrid, \\ 28040 Madrid, Spain
}

(Received 4 June 2009; accepted 23 June 2009; published online 9 July 2009)

\begin{abstract}
Indium-zinc-oxide (IZO) nanobelts have been grown by a thermal evaporation-deposition method with $\mathrm{ZnO}$ and $\mathrm{In}_{2} \mathrm{O}_{3}$ powders as precursors. The nanobelts have a superlattice structure that is explained by the formation of $\mathrm{In}-\mathrm{O}$ and $\mathrm{In} / \mathrm{Zn}-\mathrm{O}$ layers, which appears to favor the formation of nanorings. X-ray analytical methods indicate that the approximate composition of the compound is $\mathrm{Zn}_{4} \mathrm{In}_{2} \mathrm{O}_{7}$. Cathodoluminescence of the nanobelts in scanning electron microscope shows a dominant emission at $2.37 \mathrm{eV}$, which is suggested to be a characteristic band of the IZO structure. (C) 2009 American Institute of Physics. [DOI: 10.1063/1.3176974]
\end{abstract}

In the frame of the increasing activity on nanoscale electronic and optical devices a high number of doped and undoped $\mathrm{ZnO}$ elongated nanostructures with shapes of wires, rods, belts, or needles have been reported in the last years. Indium is one of the dopants of interest in $\mathrm{ZnO}$ because it is an efficient element to improve its optical and electronic properties. In particular, it is recognized that In doped $\mathrm{ZnO}$ films have good properties as transparent conductor. Indium doped $\mathrm{ZnO}$ nanobelts, ${ }^{1,2}$ nanowires, ${ }^{2-6}$ and nanospirals ${ }^{7}$ have been grown by thermal evaporation methods. A remarkable effect during thermal growth of In doped $\mathrm{ZnO}$ nanowires is the formation of a superlattice structure. ${ }^{3,6,8}$ The structure consists of alternated $\mathrm{In}-\mathrm{O}$ and In doped $\mathrm{ZnO}$ layers (or In/ $\mathrm{Zn}-\mathrm{O}$ layers) perpendicular to the $c$-axis of the wurtzite structure. Such indium-zinc-oxide, or IZO, structures have approximate composition $\operatorname{In}_{2} \mathrm{O}_{3}(\mathrm{ZnO})_{m}, m$ integer. The composition of these structures is also described as $\mathrm{Zn}_{k} \operatorname{In}_{2} \mathrm{O}_{k+3}$. The formation of such compounds implies that the physical properties of the obtained nanostructures are different from those of In doped $\mathrm{ZnO}$, with $\mathrm{In}$ on $\mathrm{Zn}$ sites without further structural changes. In this work, In- $\mathrm{Zn}-\mathrm{O}$ microplates and nanobelts with approximate composition $\mathrm{In}_{2} \mathrm{O}_{3}(\mathrm{ZnO})_{4}$, also expressed as $\mathrm{Zn}_{4} \mathrm{In}_{2} \mathrm{O}_{7}$, have been grown by an evaporationdeposition method. The nanostructures have been characterized by x-ray diffraction (XRD), scanning electron microscopy (SEM), transmission electron microscopy (TEM), high resolution transmission electron microscopy (HRTEM), energy dispersive spectroscopy (EDS), and cathodoluminescence (CL) in SEM.

$\mathrm{ZnO}$ and $\mathrm{In}_{2} \mathrm{O}_{3}$ powders with purities of $99.999 \%$ and $99.997 \%$, respectively, were used as precursors. Mixtures of $\mathrm{ZnO}-\mathrm{In}_{2} \mathrm{O}_{3}$ powders with $0.29,1.41$, or 2.07 at. $\%$ of $\mathrm{In}$ were prepared by milling the corresponding powders in a centrifugal ball mill. The mixture was then compacted under compressive load to form disk-shaped samples of about $7 \mathrm{~mm}$ diameter and $2 \mathrm{~mm}$ thickness. The $\mathrm{ZnO}-\mathrm{In}_{2} \mathrm{O}_{3}$ samples were then annealed under argon flow at $1350{ }^{\circ} \mathrm{C}$ for $15 \mathrm{~h}$. For XRD measurements a Philips diffractometer was used. SEM secondary electron and CL observations were carried out in a Leica 440, a Hitachi S2500, and a FEI Inspect SEM. The CL measurements were carried out between room tem-

\footnotetext{
${ }^{\text {a) }}$ Author to whom correspondence should be addressed. Electronic mail: balemanl@fis.ucm.es.
}

perature and liquid nitrogen temperature and EDS microanalysis was performed in a Leica 440 SEM with a Bruker AXS Quantax system. Transmission microscopy observations were performed with a JEOL JEM 3000F microscope at $300 \mathrm{kV}$. The samples were prepared by releasing the nanostructures from the disks by sonicating in butanol. Drops of the solution with nanostructures were then deposited onto microscope grids.

Thermal treatments of the compacted disks at $1350{ }^{\circ} \mathrm{C}$ lead to the growth of different micro- and nanostructures whose shapes depended on the amount of In in the precursor mixture. In samples prepared with the lowest In content, 0.29 at. $\%$, isolated hexagonal microplates are observed. In samples prepared with higher In contents a distribution of hexagonal plates and nanobelts appears on the surface. Figure 1 shows examples of both structures. Some of the belts, as that shown in Fig. 1(b), have a ring shape. In the following we refer only to the samples prepared with 1.41 and 2.07 at. \% In, which contain representative structures. XRD pattern of the treated sample corresponds to the hexagonal IZO phase $\mathrm{Zn}_{4} \mathrm{In}_{2} \mathrm{O}_{7}{ }^{9}$, and a worse matching is found with the rhombohedral $\mathrm{Zn}_{3} \mathrm{In}_{2} \mathrm{O}_{6}$ phase. EDS measurements performed in different sites of the hexagonal plates and of the nanobelts reveal an atomic ratio $\mathrm{Zn}$ :In close to 2, which supports that the composition of the structures is $\mathrm{Zn}_{4} \mathrm{In}_{2} \mathrm{O}_{7}$.

Figure 2(a) shows a TEM image of a nanobelt and Figs. 2(b) and 2(c) are HRTEM images of the regions of the nanobelt labeled as A and B. The inset in Fig. 2(a) is the electron diffraction pattern of the belt. In both HRTEM images a superlattice structure is observed. As mentioned above, such superlattices have been reported ${ }^{3,6,8}$ in In- $\mathrm{Zn}-\mathrm{O}$ nanowires and consist normally of single In-O layers separated by sev-

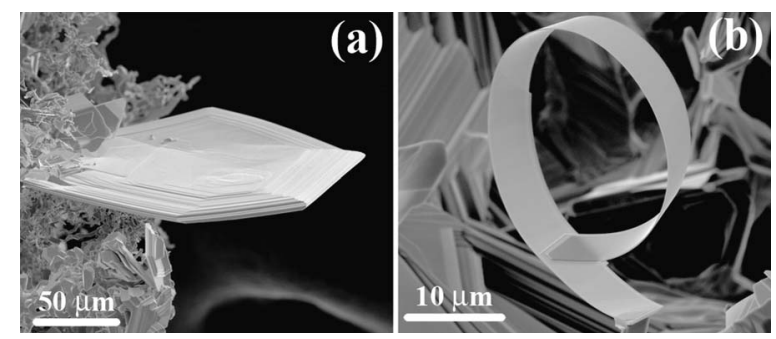

FIG. 1. (a) Hexagonal plate in a sample prepared with 1.4 at. $\%$ of In in the precursor and (b) nanobelts. 


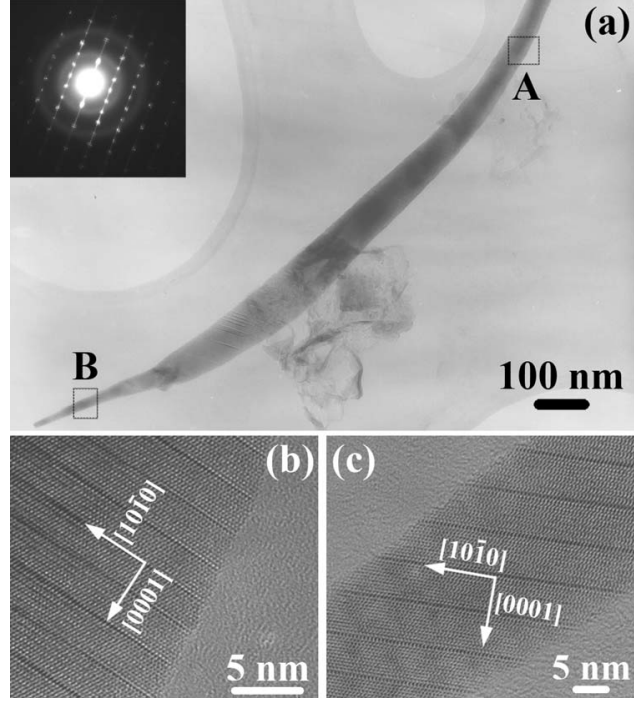

FIG. 2. (a) TEM image of a nanobelt. The inset shows the electron diffraction pattern; [(b) and (c)] HRTEM images show the superlattice structure of the regions of the nanobelt labeled $\mathrm{A}$ and $\mathrm{B}$ in (a).

eral In doped $\mathrm{ZnO}$ layers (or $\mathrm{In} / \mathrm{Zn}-\mathrm{O}$ layers) perpendicular to the $c$-axis of the hexagonal structure. The parallel array of the In/Zn-O slabs and the In-O layers along the [0001] axis minimizes the lattice strain of the In-Zn-O system. ${ }^{10}$ The stacking of the superlattices in the nanowires has been observed perpendicular or parallel to the growth direction ${ }^{3}$ but in both cases the layers are stacked along the [0001] direction.

A modulated structure has also been reported for In doped $\mathrm{ZnO}$ nanobelts wound to form nanorings. ${ }^{11,12}$ Quantitative analysis of the nanorings showed the atomic ratio In: $\mathrm{Zn}$ of about $1: 15$ suggesting In incorporation into the $\mathrm{ZnO}$ lattice, instead of the formation of the compound $\mathrm{Zn}_{4} \mathrm{In}_{2} \mathrm{O}_{7}$ observed in the nanobelts of this work. The formation of nanorings by rolling up of nanobelts is explained ${ }^{13}$ by a reduced overall dipole moment, and hence a reduction in electrostatic energy, in a circular ring. A ring is formed when this energy reduction is higher than the elastic energy increase produced by bending of the belt. The presence of the superlattice appears to favor the formation of nanorings probably by influencing this balance between electrostatic and elastic energy. In fact, nanorings were not observed in our previous works on growth, under the same conditions applied here, of elongated nanostructures of $\mathrm{ZnO}$ undoped and doped with different elements. ${ }^{14-16}$

As Figs. 2(b) and 2(c) show, the angle between the superlattice layers and the growth axis is not constant along the belt, but it changes from nearly $90^{\circ}$ to about $45^{\circ}$, showing that the crystallographic growth direction of the belt gradually deviates from [0001], which is the direction perpendicular to the layers.

SEM images show that many of the nanobelts have their origin in the hexagonal plates and other planar structures grown on the sample surface, which that the plates contain favorable nucleation sites for the nanobelt growth. Most of the nanobelts start growing in the hexagonal plate surface, which corresponds to the basal (0001) plane. This can explain that the growth direction of the nanobelts, at least in the earliest steps of growth, is [0001]. This is different from the
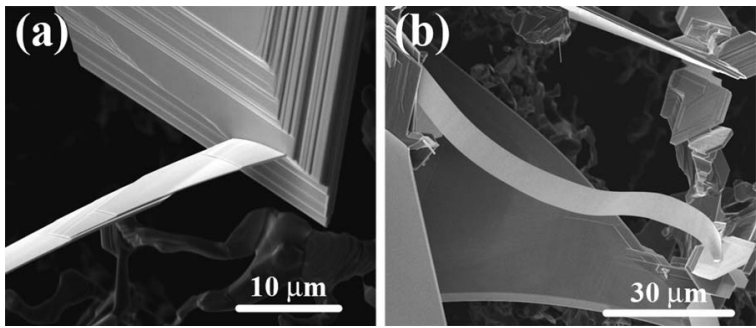

FIG. 3. [(a) and (b)] SEM images showing connections between plates and nanobelts.

case of $\mathrm{ZnO}$ nanobelts where growth directions $\langle 10 \overline{10} 0\rangle$ or $\langle 11 \overline{2} 0\rangle$ have been reported. ${ }^{2,7,11,12}$

Figure 3 shows examples of the connection between plates and nanobelts. In Ref. 2, indium doped belts have been grown by a vapor-liquid-solid process with $\mathrm{Au}$ as catalyst, and the observation that some belts extend from hexagonal plates is explained by the formation of a Au-Zn-In ternary alloy at a face of the plate, which act as catalyst for the belt growth. In the present work, a catalyst free growth method has been used and the growth of nanobelts from certain sites of the plates appears to be related to the presence of In. We suggest that local excess or segregation of In at the surface of the plate favors the growth of the nanobelts. A similar effect, surface segregation of dopant, has been proposed ${ }^{17}$ to explain the growth of side $\mathrm{ZnO}$ nanowires from a central $\mathrm{Sn}$ doped $\mathrm{ZnO}$ wire.

EDS mapping shows an inhomogeneous distribution of $\mathrm{Zn}$ in the hexagonal plates, as is shown in Fig. 4(a). In the lateral faces an enhanced $\mathrm{Zn}$ signal is observed, which is also revealed in the $\mathrm{Zn}$ profile along a line crossing several steps, while the In profile shows a rather constant distribution [Figs. 4(b) and 4(c)]. EDS measurements on the junction of the plate and the nanobelt shown in Fig. 3(a) shows a higher content of In in the nanobelt, with a ratio $\mathrm{Zn}$ :In of 2 while in the plate the ratio is about 2.3. The higher In content in the nanobelt is explained by the formation of the superlattice with composition $\mathrm{Zn}_{4} \mathrm{In}_{2} \mathrm{O}_{7}$, which implies the ratio value of 2 .

Luminescence of In doped $\mathrm{ZnO}$ nanostructures has been previously reported. Indium related redshift, of about $0.1-0.2$ $\mathrm{eV}$, of the near band gap photoluminescence (PL) emission was found in nanobelts ${ }^{1}$ and nanowires. ${ }^{3-5}$ PL spectra of the nanowires with modulated structure of Ref. 8 show the $\mathrm{ZnO}$ near band gap emission at about $3.25 \mathrm{eV}$ while the CL spectra show also the often reported defect band, in the range $2.0-2.8 \mathrm{eV}$, of this material.
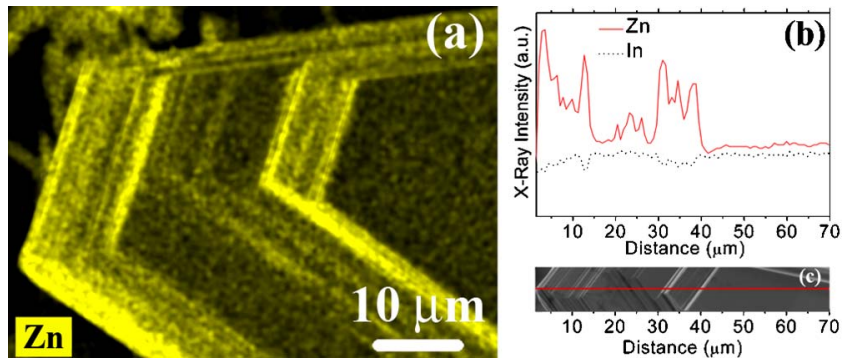

FIG. 4. (Color online) (a) EDS Zn map of a plate. Higher Zn signal is observed in the lateral faces. (b) Profiles of EDS Zn (solid line) and In (dotted line) signals across the line shown in (c). 

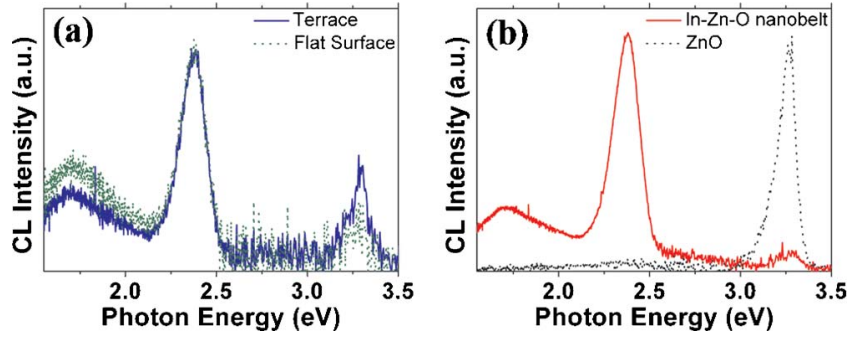

FIG. 5. (Color online) (a) CL spectra at $80 \mathrm{~K}$ recorded on a terrace (solid line) and on the flat surface (dotted line) of a plate and (b) CL spectra at $80 \mathrm{~K}$ of a nanobelt (solid line) and of pure $\mathrm{ZnO}$ (dotted line).

Figure 5(a) shows the CL spectra recorded on the flat surface and in a step, or terrace, of a hexagonal plate. The main band is peaked at $2.37 \mathrm{eV}$, and a weaker band is observed at about $1.69 \mathrm{eV}$. The $\mathrm{ZnO}$ near band edge emission is very weak in the spectrum of the flat surface but is clearly observed in the spectrum of the steps, which, as measured by EDS, have a lower In content. Figure 5(b) shows the CL spectrum recorded on a nanobelt, with the main emission at $2.37 \mathrm{eV}$. For comparison, a CL spectrum of pure $\mathrm{ZnO}$ is also shown in Fig. 5(b). These results suggest that the 2.37 band is characteristic of the $\mathrm{In}-\mathrm{Zn}-\mathrm{O}$ structure, the $\mathrm{ZnO}$ band edge emission, which is negligible in the spectra from nanobelts which have the superlattice structure with $\mathrm{Zn}_{4} \mathrm{In}_{2} \mathrm{O}_{7}$ composition. The $2.37 \mathrm{eV}$ emission is within the spectral range in which the $\mathrm{ZnO}$ defect band, is observed. However, the $\mathrm{ZnO}$ defect band is a very broad complex band extending in the approximate range $2.0-2.8 \mathrm{eV}$, while the $2.37 \mathrm{eV}$ band of the $\mathrm{In}-\mathrm{Zn}-\mathrm{O}$ structures is within the range $2.3-2.5 \mathrm{eV}$ with a full width at half maximum of $0.15 \mathrm{eV}$, much narrower than the usually reported defect band of $\mathrm{ZnO}$, specially in CL spectra of nanostructures. ${ }^{14,18}$ The $2.37 \mathrm{eV}$ appears to be characteristic of the In- $\mathrm{Zn}-\mathrm{O}$ compound forming the plates and nanobelts. There is, however, no information enabling to associate this emission with specific electronic features of $\mathrm{Zn}_{4} \mathrm{In}_{2} \mathrm{O}_{7}$.

In summary, IZO microplates and nanobelts have been grown by a catalyst free evaporation deposition method. The nanobelts have a superlattice structure, explained by the formation of In-O and In/Zn-O layers. This superlattice structure appears to favor the formation of ring-shaped nanobelts. XRD and EDS measurements indicate that the formed compound is $\mathrm{Zn}_{4} \mathrm{In}_{2} \mathrm{O}_{7}$. Nanobelts have been found to generate at specific sites of the microplates by a mechanism suggested to involve In segregation. CL shows a dominant emission band peaked at $2.37 \mathrm{eV}$, which is probably characteristic of the structure of the nanobelts.

This work was supported by MEC (Project No. MAT2006-01259).

${ }^{1}$ J. Jie, G. Wang, X. Han, Q. Yu, Y. Liao, G. Li, and J. G. Hou, Chem. Phys. Lett. 387, 466 (2004)

${ }^{2}$ H. J. Fan, B. Fuhrmann, R. Scholz, C. Himcinschi, A. Berger, H. Leipner, A. Dadgar, A. Krost, S. Christiansen, U. Gösele, and M. Zacharias, Nanotechnology 17, S231 (2006).

${ }^{3}$ J. Jie, G. Wang, X. Han, and J. G. Hou, J. Phys. Chem. B 108, 17027 (2004).

${ }^{4}$ L. Xu, Y. Su, Y. Chen, H. Xiao, L. Zhu, Q. Zhou, and S. Li, J. Phys. Chem. B 110, 6637 (2006).

${ }^{5}$ L. M. Li, C. C. Li, Z. F. Du, B. S. Zou, H. C. Yu, Y. G. Wang, and T. H. Wang, Nanotechnology 18, 225504 (2007).

${ }^{6}$ L. Wu, X. Zhang, Z. Wang, Y. Liang, and H. Xu, J. Phys. D: Appl. Phys. 41, 195406 (2008).

${ }^{7}$ H. Gao, H. Ji, X. Zhang, H. Lu, and Y. Liang, J. Vac. Sci. Technol. B 26, 585 (2008).

${ }^{8}$ C. W. Na, S. Y. Bae, and J. Park, J. Phys. Chem. B 109, 12785 (2005).

${ }^{9}$ JCPDS Card No. $20-1438$.

${ }^{10}$ Y. F. Yan, J. L. F. Da Silva, S. H. Wei, and M. Al-Jassim, Appl. Phys. Lett. 90, 261904 (2007).

${ }^{11}$ X. Y. Kong, Y. Ding, R. Yang, and Z. L. Wang, Science 303, 1348 (2004).

${ }^{12}$ Y. Ding, X. Y. Kong, and Z. L. Wang, Phys. Rev. B 70, 235408 (2004).

${ }^{13}$ X. Y. Kong and Z. L. Wang, Appl. Phys. Lett. 84, 975 (2004).

${ }^{14}$ J. Grym, P. Fernández, and J. Piqueras, Nanotechnology 16, 931 (2005).

${ }^{15}$ Y. Ortega, P. Fernández, and J. Piqueras, Nanotechnology 18, 115606 (2007).

${ }^{16}$ Y. Ortega, P. Fernández, and J. Piqueras, J. Appl. Phys. 105, 054315 (2009).

${ }^{17}$ J. G. Wen, J. Y. Lao, D. Z. Wang, T. M. Kyaw, Y. L. Foo, and Z. F. Ren, Chem. Phys. Lett. 372, 717 (2003).

${ }^{18}$ L. Khomenkova, P. Fernández, and J. Piqueras, Cryst. Growth Des. 7, 836 (2007). 